\title{
Review of Paediatrics Inpatient at a Zonal Hospital
}

\author{
Paudel KM'1 , Sharma $S^{2}$ \\ ${ }^{1}$ Dr. Kiran Mani Paudel, MBBS, MD, Senior Consultant Paediatrician, ${ }^{2}$ Dr. Sindhu Sharma, MBBS, Medical Officer, Department \\ of Paediatrics. Both from Lumbini Zonal Hospital.
}

Address for correspondence: Dr. Kiran Mani Paudel, E-mail: kmp2588@yahoo.com

\begin{abstract}
Introduction: Childhood illnesses cause significant number of admissions in different level hospitals. This retrospective study was undertaken to analyze the morbidity pattern in the Paediatric ward at a Zonal Hospital with aim that the results obtained will help in planning, prioritizing and implementing preventive, promotive and curative health care activities of the children in resource poor community. Materials and Methods: This study was carried out retrospectively for one year from July/Aug 2010 June/July 2011. Age, sex, diagnosis, month of admission, duration of admission and the frequency of diseases were evaluated. Results: A total number of 977 patients were admitted during the study period. There were $579(59 \%)$ male and $398(41 \%)$ female children. Less than five years age group accounted for $569(58 \%)$ excluding the neonates. In the study period, respiratory tract infections were the commonest cause of admission 309(31.6\%), gastrointestinal including diarrhoeal diseases were $278(28.5 \%)$, enteric fever comprised of $69(7 \%)$, and other diseases comprised of about 390(39.5\%). Of the total admissions, CNS diseases comprised of $128(13 \%)$ of which $29(3 \%)$ were meningitis and meningoencephalitis. Sixty seven (52\%) of the total CNS cases were due to febrile convulsion. Renal and cardiovascular diseases were $8.5 \%$ and $1.5 \%$ respectively. Conclusion: Children under five years of age being the most common age group amongst all, with respiratory and gastrointestinal diseases still being the most predominant cause of paediatric morbidity; community level interventions including $\mathrm{IMCl}$ should be strengthened for reducing hospital admissions, along with allocation of hospital beds and supplies as per morbidity pattern.
\end{abstract}

Key words: Paediatric Inpatient, Morbidity, IMCI

\section{Intoduction}

W orldwide children younger than age 15 years account for $28 \%$ of the total population'. A large proportion of the Nepalese population (37\%) is under age 15 . Eleven percent of the population is under five years ${ }^{2}$.

Childhood illnesses comprise major portion of hospital admissions in the world with significant mortality. About 7.6 million under-five children died in 2010, three-quarters of which are mainly due to preventable causes: neonatal conditions, pneumonia, diarrhoea, malaria, and measles ${ }^{3}$. Pneumonia and diarrhoeal diseases are the two biggest killers of children under 5 years old, accounting for $18 \%$ and $15 \%$ of all deaths respectively in $2008^{4}$. Pneumonia is the largest single cause of death in children less than five years of age, and is responsible for nearly 1.4 million deaths every year. Diarrhoeal diseases account for 840,000 deaths among under-five children in the world ${ }^{3}$.
As major population of our country is comprised of children; knowledge of morbidity and mortality pattern of children in different part of the country is essential for planning, programming and implementing preventive, promotive and curative healthcare activities of the country.

Few studies on childhood admission profile in paediatric wards have been done in Nepal ${ }^{5,6,7}$.

Morbidity pattern can vary in different seasons and regions. As such type of study was not performed in this region of the country; this study was conducted with an objective to determine the disease pattern of children prevalent in this region of Nepal.

\section{Materials and Methods}

This was a retrospective study conducted in paediatric patients admitted and treated at Lumbini Zonal Hospital in Butwal, which is a referral hospital of 
this area with 134 beds and specialist services. Lumbini Zonal Hospital is situated in Butwal, Rupandehi. Being the zonal hospital it is the major referral centre for various districts like Nawalparasi, Kapilbastu, Arghakhanchi, Palpa, Gulmi, Dang, Pyuthan and Rupandehi itself. The data were collected from the records of patients admitted in paediatric ward of the hospital over one year (July/August 2010 to June/July 2011). The patients were admitted through emergency and outpatient departments of the hospital. The patients were managed by medical officers and paediatrician in emergency department and by paediatrician in paediatric ward. The details of each case were taken from patients' case records. Name, age, sex, address, date of admission, hospital stay and diagnosis were recorded from the record sheet. Diagnosis was made as per International classification of disease. Admitted neonates up to 28 days of life were not included in the study. Patients needing ICU support and patient party requesting for referral were referred to higher centers from emergency department and out patients department (OPD) and excluded from the study. The data were entered in a computer database and analyzed using excel.

\section{Results}

A total no of 1281 patients were admitted during the study period out of which 304 patients were neonates and excluded from the study. Out of 977 children up to 14 years, males were $579(59 \%)$ and females were 398(41\%) as shown in Figure 1.

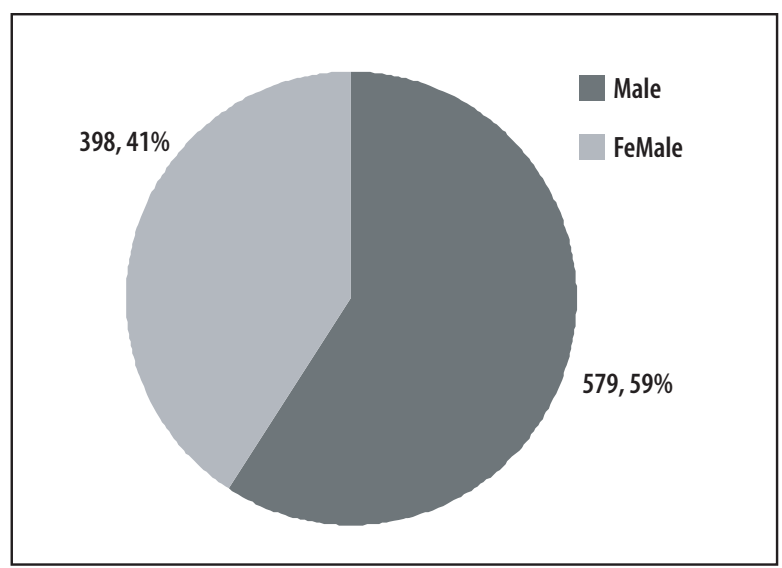

Fig 1: Gender Distribution of patients

As shown in Fig. 2, less than five years age group accounted for 569(58\%) excluding the neonates.

In the study period, respiratory infection cases were $309(31.6 \%)$, gastrointestinal including diarrheal diseases were $278(28.5 \%)$. Sixty nine cases of enteric fever comprised $24.8 \%$ of gastrointestinal diseases and $7 \%$ of total admissions. Acute gastroenteritis cases comprised of $19.2 \%$ of the total admissions which included 3 cases

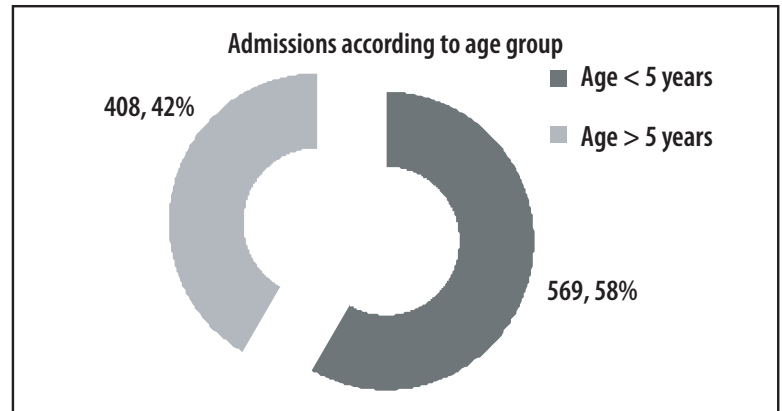

Fig 2: Total number of Admissions according to the age group.

of cholera as well. Out of acute gastroenteritis cases two third cases were below 2 years of age and around $80 \%$ of cases were below 5 years. Around $60 \%$ of admissions were due to $\mathrm{Gl}$ and respiratory causes. Other diseases other than respiratory and gastrointestinal diseases comprised 390(39.5\%) amongst the total admissions.

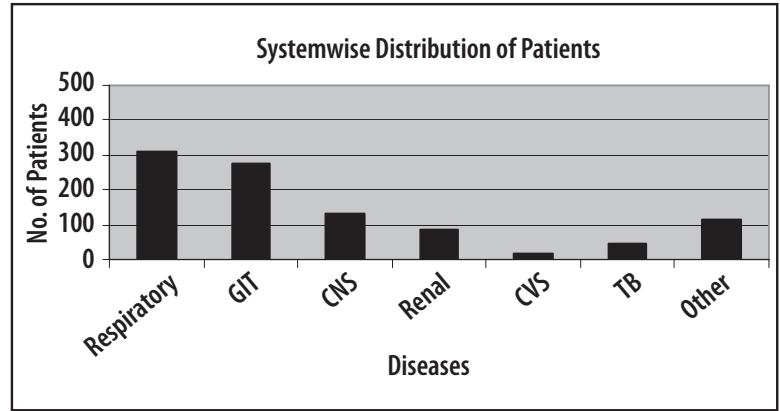

Fig 3: Showing System wise Frequency of Diseases.

As shown in Fig. 3, respiratory tract infections were the commonest cause of admissions in hospital followed by gastrointestinal diseases. Among other diseases, Central Nervous System (CNS) cases were 128(13\% of total admissions) out of which febrile convulsions were 67 which is $52 \%$ of the total CNS cases and $6.9 \%$ of the total admissions. Of the total CNS cases $22.6 \%$ cases were meningoencephalitis including 4 cases of mumps meningitis and few cases of seizures due to neurocysticercosis, epilepsy and few cases of Guillene Barre Syndrome (GBS). Renal cases were $84(8.5 \%$ of total admission) out of which AGN was $35(41 \%$ of renal cases). There were 48 cases of tuberculosis $(4.9 \%$ of total admission) out of which tuberculosis of chest and abdomen were almost equal in numbers. There were 15 cases of Cardio Vascular System (CVS) (1.5\% of total cases), out of which two third cases were acute rheumatic fever. Other cases were $113(11.5 \%$ of total admissions); which included snakebites, malaria, septicemia, dengue, ITP, HSP, anemia, JRA etc.

Mean age of admitted patients was 57.68 months. Highest number of admissions was in the months of Mar/Apr and Aug/Sep and lowest admissions were in the months of Dec to February as seen in Fig. 4. 


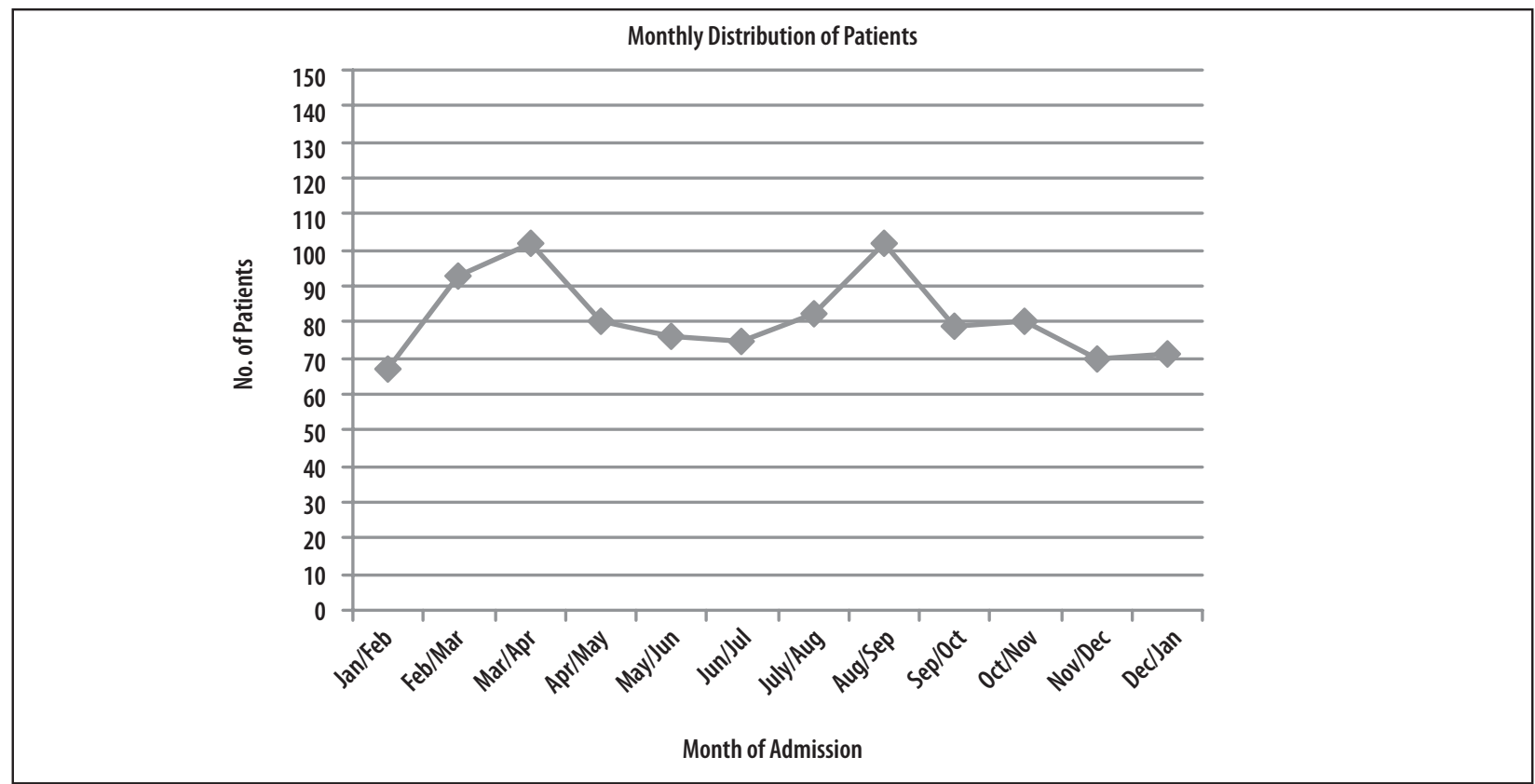

Fig 4: Line diagram showing seasonal trend in admissions (Total).

The highest number 100 (32.3\%) of respiratory diseases were admitted in months of September to November as shown in Fig. 5 as below.

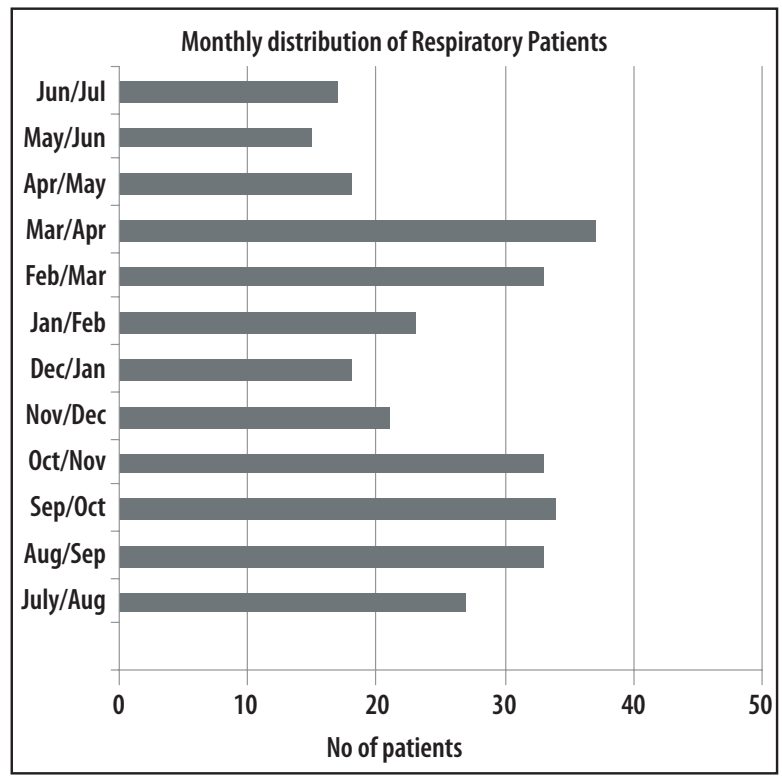

Fig 5: Graph showing Frequency of Respiratory Diseases.

One third cases of diarrhoea were seen during Feb/March and Mar/Apr. Minimum hospital stay of the patient was one day and maximum was 12 days with mean 4.1 days. As depicted in Table 1, majority patients stayed in hospital for less than three days.

Geographically maximum number of patients came from Rupandehi district 585(59\%) followed by Nawalparasi, Kapilvastu and other districts of the region.
Table 1: Showing days of stay in Hospital

\begin{tabular}{|c|c|}
\hline No of patients & $\begin{array}{c}\text { Duration of Hospital } \\
\text { stay (Days) }\end{array}$ \\
\hline 346 & $1-3$ \\
\hline 232 & 4 \\
\hline 247 & 5 \\
\hline 152 & $6+$ \\
\hline
\end{tabular}

\section{Discussion}

In the study period, among 977 admitted children, 579 (59\%) were males and 398 (41\%) were females. The male to female ratio was 1.45 ; lower than $(1.67)^{6},(1.78)^{7}$, and $(2.6)^{8}$ that was obtained in the study conducted among 761, 312 and 9205 patients respectively in Kathmandu Medical College Teaching Hospital (KMCTH), Dhulikhel Hospital (Kathmandu University Teaching Hospital) and paediatric emergency unit in Chandigarh hospital respectively. The ratio is same as that of a study conducted in Nepal Medical College Teaching Hospital Attarkhel Jorpati ${ }^{5}$. Less numbers of girl children admissions may be due to the parents' preferences to bring them to hospital, on boys over girls.

Less than five years age patients admitted in the paediatric ward were $569(58 \%)$ of the total number of admissions which is comparable to a study done in Kathmandu Medical College ${ }^{6}$ but is more than the number in a study done in Nepal Medical College ${ }^{5}$. The least number of admitted patients were the age of more than 12 years which is comparable to a study conducted in Nepal Medical College Teaching Hospital Attarkhel Jorpati; Kathmandu ${ }^{5}$. 
In the study period; 309(31.6\%) patients comprised of respiratory tract infections including Pneumonia, Acute Bronchiolitis and Asthma. Acute Gastroenteritis comprised of 278 (28.5\%). Few other studies $5,6,7,9,10,11,12$ showed similar findings with respiratory and diarrheal diseases on top of the morbidity list.

Tuberculosis comprised of 48 (4.9\%) of the admitted cases that was comparatively more than in the studies done in Kathmandu Medical College Teaching hospital (KMCTH) ${ }^{6}$ (2.4\% of 489 patients), Dhulikhel Hospital (3.2\% of 312 patients) ${ }^{7}$ and Nepal Medical College Teaching Hospital NMCTH (4.1\% of 453 patients) ${ }^{5}$. These figures were statistically low in all four studies in our country as compared to the study done by Murray $\mathrm{CJ}^{13}$ which vary between $15 \%$ in developing countries and below $5 \%$ in the United States and European Countries. The low incidence in our studies could be due to difficulty in estimating the TB burden in children. Challenges for doing so include difficulties in establishing a definitive diagnosis, the increased presence of extrapulmonary disease in young children, the lack of standard definition, and the low priority on the public health agenda compared to adult TB ${ }^{14}$. Also, the number of tuberculosis could be less due to the fact that tubercular lymphadenitis cases were not admitted in the ward as they were treated as out-patients. Lack of education, poor socioeconomic status, lack of health awareness and the belief in traditional healers were the reasons for late presentation contributing to the morbidity and mortality due to the diseases.

Febrile convulsions were seen in $6.9 \%$ of the total cases and in $67(52 \%)$ of the CNS diseases which was comparable to the study conducted in $\mathrm{KMCTH}^{6}$ (50\%) and Dhulikhel Hospital ${ }^{7}$ (48.27\%) but less than in Nepal Medical College ${ }^{5}(60 \%)$ study. Worldwide cumulative incidence of febrile convulsion among children ranges from about $1 \%$ in China to more than $8 \%$ in Japan ${ }^{15}$. Of the total CNS cases $22.6 \%$ cases were meningoencephalitis including four cases of aseptic meningitis secondary to mumps which is $3 \%$ of total admissions. Out of $84(8.5 \%)$ renal cases, $35(41 \%)$ were nephritic syndrome and $25(2.6 \%)$ were nephrotic syndrome and $24(2.5 \%)$ were urinary tract infections.

Out of $15(1.5 \%)$ cardiac patients, majority were cases of acute rheumatic fever out of which three cases presented with only chorea as the sole manifestation of Acute Rheumatic Fever. Two cases of infective Endocarditis were also treated during the period. Majority of the cardiac patients were of rheumatic origin and this is attributed to the poor socioeconomic status leading to unhygienic living conditions and overcrowded households that predisposes to the spread of streptococcal infections and poor and under-nutrition of our patients that alter the immunological response in increasing the susceptibility to infections ${ }^{16}$. Other cases were $113(11.5 \%$ of total admissions), which included 23 cases of snakebite, 20 cases of malaria, 18 cases of septicemia, 13 cases of anemia, 11 cases of kerosene poisoning, 8 cases of HSP, 6 cases of dengue, 4 cases of ITP etc.

Among the respiratory cases, most were pneumonia followed by acute bronchiolitis. Acute bronchiolitis were admitted mainly during the winter season, this might have been due to seasonal outbreak of respiratory viral infection particularly respiratory syncytial virus and infl uenza viruses ${ }^{17}$. Diarrhoeal diseases were mostly seen during rainy season as found in other study ${ }^{12}$. Sporadic cases of cholera were seen in July (1) and August (2) which were similar to the study done in Karachi, Pakistan by Sheikh Et.al published in 1997 in which the Cholera cases peaked during April to October ${ }^{18}$.

In the study period, it was seen that maximum number of patients i.e. $346(35 \%)$ stayed less than four days. About $24 \%$ stayed for four days and $25 \%$ stayed for five days. Patients staying six days or more were only $152(15.5 \%)$ which is comparable to a study conducted in Nepal Medical College Teaching Hospital Attarkhel Jorpati ${ }^{5}$. Patients with complication of pneumonia, meningitis, and nephritic syndrome and enteric fever were found to have longer duration of stay.

In the study period, the highest number of admissions was in the months of July to October. This may be because of increased number of diarrheal and respiratory diseases during this hot and rainy season. The number of admission was lowest in Jan/Feb corresponding to cold season.

World Health Organization (WHO) had started Integrated Management of Childhood Illnesses (IMCI) strategy to address diagnosis, management and preventive aspects of major killer diseases in under five children in $1992^{19}$ which helped reducing under- five mortality worldwide including diarrhea and pneumonia related deaths. The number of under-five deaths worldwide has declined from more than 12 million in 1990 to 7.6 million in $2010^{20}$ due to community level interventions including $\mathrm{IMCl}$.

Taking into account high rate of morbidity and mortality due to diarrheal and respiratory illnesses; Nepal government began National control of Diarrheal Diseases (CDD) program in 1983 and National Control of Acute Respiratory Illnesses (ARI) program in 1987 which were later merged with IMCl strategy from 1995 and gradually expanded throughout the country ${ }^{21}$. 
Although pneumonia and diarrhea related deaths have been decreased significantly over the last few years causing decrease in under- five mortality from 87 in 1996 to 54 in 2011 in $\mathrm{Nepal}^{2}$, it is still high as compared to developed countries like Sweden and Finland who have three per thousand under five mortality ${ }^{1}$. Although case fatality due to diarrhea has decreased from 1 per 1000 under five children in 1995/96 to 0.04 in 2009/10 its incidence are still 598 per 1000 under five children in 2009/10 posing threat for management. Although percent of severe pneumonia and pneumonia has decreased from $13 \%$ and $54 \%$ respectively in 1995/96 to $0.4 \%$ and $30 \%$ in $2010 / 11$, it is still high number with $28 \%$ of total ARI cases needing treatment in health facilities in 2010/11 increasing burden to bed scarce hospitals. At the same time, ARI incidence has increased from 104 per 1000 under five children in 1995/96 to 824 in 2010/11 reflecting the burden of problem at present ${ }^{22}$.

Acute respiratory illnesses are high in developed countries as well but pneumonia needing admissions is less there as compared to ours. This could be due to overcrowding in our families, use of firewood in cooking and poor hygienic conditions of the rural families causing secondary bacterial infections. High number of diarrhea morbidity and admissions in hospitals could be due to contaminated water, as only $46 \%$ of households in urban areas and $13 \%$ in rural areas treat drinking water ${ }^{2}$; unhygienic practices in food preparations and poor excreta disposal causing water and food material contamination, as only two in five households (38\%) have an improved (not shared) toilet facility and $36 \%$ of households still use a bush or open field for defecation ${ }^{2}$. In cities contamination of water supply system with water carriage system could be the cause for more incidences. Similarly hepatitis and enteric fever cases are due to poor hygiene, food and water contamination.

In difference from other studies conducted in Kathmandu, climate related morbidities like malaria, snakebite, dengue are present in this part. Snake bite cases are more prevalent in poor communities with poor housing conditions and on those working on fields. Community awareness programs preventing bites including improving housing conditions is needed. Similarly, mosquito borne diseases like malaria, encephalitis, and dengue are present in this part because of good climatic condition of the region for breeding of mosquito. Health education to people for improving environmental sanitation along with destroying mosquito breeding through spray, use of net for protecting from bites is necessary.

\section{Conclusion}

Children under five being the most common age group amongst all, with majority of morbidity problems related to poor hygiene, contaminated foods and water, overcrowding and poor health education of the people; related ministries like Health, Education, Construction and local development should have coordinated efforts to overcome the health related issues and community health interventions including $\mathrm{IMCl}$ should be strengthened further to reduce hospital admissions and mortality, along with adequate allocation of beds and medical supplies in the hospitals as per morbidity pattern is recommended.

\section{Acknowledgement}

I would like to thank Medical Superintendent for allowing me to conduct study. I am thankful to Mr. Ram Bahadur Malla for his secretarial help.

\section{Funding: Nil \\ Conflict of interest: None}

Permission from IRB: Permission taken from Medical Superintendent of the Hospital

\section{References}

1. Bonita F, Stanton and Richard E, Behrman. Overview of Pediatrics: In Kliegman RM, Behrman RE, Schor NF, St. Geme III JW and Stanton BF. Nelson Textbook of Pediatrics. 19th ed. Philadelphia: W.B. Saunders Company; 2011: 1-13

2. Ministry of Health and Population (MOHP) [Nepal], New ERA, and ICF International Inc. 2012. Nepal Demographic and Health Survey 2011. Kathmandu, Nepal: Ministry of Health and Population, New ERA, and ICF International, Calverton, Maryland.

3. WHO. World Health Organisation. Child health epidemiology. [homepage on the internet]. c2012 [updated 2012; cited 2012 May 5]. Available from http://www.who.int/maternal_child_adolescent/ epidemiology/child/en/index.html. Accessed 12th September 2012.

4. WHO. World Health Organisation. World Health Statistics 2011:14-19

5. Upadhyay S, Sharma A, Rijal P, Shrestha S. Review of Paediatrics In-Patient at Nepal Medical College and Teaching Hospital. J Nepal Paedtr Soc 2011;31(1):2529.

6. Bajracharya $B L$, Joshi $P$, Manandhar DS, Baral MR. Review of Paediatrics Inpatient at Kathmandu Medical College. J Kathmandu Med Col 2002;4:43-49.

7. Nepali N, Ghimire R, Shrestha RPBS. Review of Paediatrics Inpatient at Dulikhel Hospital, Kathmandu University Teaching Hospital. J Nepal Paedtr Soc 2007; 26:16-19. 
8. Salaria $M$, Singhi S. Profile of patients attending pediatric Emergency service at Chandigarh. Indian J Pediatr 2003; 70 (8):621-24.

9. Singhi S, Jain V, Gupta G. Pediatric emergencies at a tertiary care hospital in India. J Trop Pediatr 2003;49(4):207-11.

10. Garg P. Pediatric Hospitalizations at two Different Setting Community Hospitals in North India: Implications for Regionalization of Care. Indian J Pediatr 2009;76(7):711-16.

11. Abdullah HB, M Rahman, K. Zaman et al. A Population-based Study of Hospital Admission Incidence Rate and Bacterial Aetiology of Acute Lower Respiratory Infections in Children Aged Less Than Five Years in Bangladesh. J Health Popul Nutr 2007;25(2):179-188.

12. Mohapatra SC, Mohapatra P, Singh IJ, Gaur SD. Epidemilogy of gastrointestinal and Respiratory tract Disease in a rural areas of Varanasi (India) Eur J of Epid 1989; 5(1):117-22.

13. Murray $C J$, Styblo $K$, Rouillon $A, T B$ in developing countries:burden,intervention and cost. Bull Int Union Tuberc Lung Dis 1990;65(1):6-24.

14. Cooreman E. Global epidemiology of Pediatric Tuberculosis. In:Seth V,Kabra SK. Essentials of Tuberculosis in children, 3rd Ed, Jaypee;2006:11.

15. Hauser WA, The prevalence and incidence of convulsive disorder in children. Available on http://www.ncbi.nlm.nih.gov/ pubmed/8275976. Accessed on $27^{\text {th }}$ September 2012.

16. Tandon R. Rheumatic Heart Disease. In: Ghai O.P, Gupta P, Paul V.K, Essential Pediatrics, 6th Ed,New Delhi, CBS publishers;2004:375.

17. Chew F.T Doraisingham S, Ling A.E, Kumarrasingha G, Lee BW. Seasonal Trends of Viral Respiratory Tract Infection In the Tropics. Epidemiol Infect 1998; 121:121-28.

18. Sheikh A, Khan A, Malik T, Fisher-Hoch SP. Cholera In Developing Megacity, Karachi, Pakistan. Epidemiol Infect 1997;119(3):287-92.

19. WHO. World Health Organisation.WHO/UNICEF Strategy of integrated management of childhood illnesses (IMCI) [homepage on the internet]. c2012 [updated 2007; cited 2012 May 5]. Available from http://www.icatt-training.org/ IMCI/AboutIMCI / tabid/84/Default.aspx. Accessed 15 ${ }^{\text {th }}$ Sept 2012.

20. UNICEF. United Nations Children's Fund. Levels \& Trends in Child Mortality Report 2011: 1.

21. Child Health Division, Department of Health Services, Ministry of Health. Diarrhoeal diseases; Acute respiratory infections; and Integrated management of childhood illnesses. In: The Child Health Profile of Nepal 2003. Kathmandu 2003:35$42,54$.

22. Annual Report. Department of Health Services, Ministry of Health and population, Government of Nepal 1995/1996, 2010/2011.

\section{How to cite this article?}

Paudel KM, Sharma S. Review of Paediatrics Inpatient at a Zonal Hospital. J Nepal Paediatr Soc 2012;32(3):239-244. 